\title{
МУТАНТ ФОТОТОКСИЧНОГО БЕЛКА КILLERRED, НЕ ФОРМИРУЮЩИЙ DSRED-ПОДОБНОГО ХРОМОФОРА
}

\section{Д. А. Горбачев, К. С. Саркисян $\bowtie$}

Институт биоорганической химии имени М. М. Шемякина и Ю. А. Овчинникова, Москва, Россия

Генетически кодируемые фотосенсибилизаторы на основе флуоресцентных белков способны производить активные формы кислорода при облучении светом, и потому их широко используют в качестве оптогенетических инструментов. Разработанные на сегодняшний день фотосенсибилизаторы с зеленой флуоресценцией обладают неоптимальными свойствами. Целью настоящей работы был поиск новых вариантов флуоресцентных белков с эффективным созреванием хромофора и высокой фототоксичностью. С помощью случайного мутагенеза фототоксичного флуоресцентного белка KillerRed и направленной эволюции в E. coli получен белок с хромофором на основе тирозина, флуоресцирующий в зеленой области спектра. Новый белок, несущий мутации I64L, D114G и T115S, не формирует DsRed-подобного хромофора и может быть использован как базовый генотип для разработки новых спектрально отличных от KillerRed генетически кодируемых фотосенсибилизаторов.

Ключевые слова: фотосенсибилизатор, флуоресцентный белок, KillerRed, мутагенез, гипсохромный сдвиг, оптогенетика

Финансирование: работа не была бы опубликована без поддержки грантом РФФИ 18-04-01173 и грантом Президента РФ 075-15-2019-411. Исследования частично выполнены на оборудовании ЦКП ИБХ РАН.

Благодарности: авторы признательны Центру высокоточного редактирования и генетических технологий для биомедицины (Москва) за помощь в методах исследования.

Информация о вкладе авторов: К. С. Саркисян, Д. А. Горбачев - планирование проекта, проведение экспериментов, анализ данных, подготовка рукописи статьи. Вклад авторов в работу равнозначен на всех этапах.

Соблюдение этических стандартов: в настоящей работе не проводили экспериментов на животных или людях, результаты не представляют интерес для создания технологий двойного назначения.

$\bigotimes$ Для корреспонденции: Карен Сергеевич Саркисян

ул. Миклухо-Маклая, 16/10, оф. 34/632, г. Москва, 117997; karen.s.sarkisyan@gmail.com

Статья получена: 08.12.2019 Статья принята к печати: 18.12.2019 Опубликована онлайн: 20.12.2019

DOI: 10.24075 /vrgmu.2019.084

\section{A MUTANT OF THE PHOTOTOXIC PROTEIN KILLERRED THAT DOES NOT FORM DSRED-LIKE CHROMOPHORE}

Gorbachev DA, Sarkisyan KS凶

Shemyakin-Ovchinnikov Institute of Bioorganic Chemistry, Moscow, Russia

Genetically encodable photosensitizers based on fluorescent proteins produce reactive oxygen species when illuminated with light. Although widely used as optogenetic tools, existing photosensitizers with green fluorescence possess suboptimal properties motivating for a search of new protein variants with efficient chromophore maturation and high phototoxicity. Here we report a mutant of the phototoxic fluorescent protein KillerRed protein with fluorescence in the green part of the spectrum. The mutant variant carries mutations I64L, D114G, and T115S and does not form a DsRed-like chromophore. The protein can be used as a template to create new genetically encodable photosensitizers that are spectrally different from KillerRed.

Keywords: photosensitizer, fluorescent protein, KillerRed, mutagenesis, hypsochromic shift, optogenetics

Funding: this work would not have been published without the generous support and the strict publication requirements of the Russian Foundation for Basic Research grant 18-04-01173. KSS is supported by the president fellowship 075-15-2019-411. Experiments were partially carried out using the equipment provided by the Institute of Bioorganic Chemistry of the Russian Academy of Sciences Core Facility (CKP IBCH; supported by Russian Ministry of Education and Science Grant RFMEFI62117X0018).

Acknowledgements: we thank to the Center for Precision Genome Editing and Genetic. Technologies for Biomedicine (Moscow) for the genetic research methods Author contribution: Sarkisyan KS, Gorbachev DA — conceived and planned the project, performed the experiments, analysed data and prepared the manuscript Compliance with ethical standards: no animal or human subjects were used in this study.

$\square$ Correspondence should be addressed: Karen S. Sarkisyan

Miklukho-Maklaya, 16/10, of. 34/632, Moscow, 117997; karen.s.sarkisyan@gmail.com

Received: 08.12.2019 Accepted: 18.12.2019 Published online: 20.12.2019

DOI: $10.24075 /$ brsmu.2019.084

Флуоресцентные белки широко используют как генетически кодируемые метки в технологиях оптического мечения живых систем [1]. Поскольку хромофор в таких белках находится внутри глобулы и защищен от окружающего растворителя, большинство существующих флуоресцентных белков являются пассивными репортерными молекулами облучение их светом незначительно влияет на физиологию клетки.

В то же время на основе белка anm2CР было разработано уникальное семейство генетически кодируемых фотосенсибилизаторов - фототоксичных флуоресцентных белков, производящих при облучении активные формы кислорода, способные убить клетку [2].
В фототоксичных фрлуоресцентных белках обнаруживается заполненный молекулами воды канал, соединяющий находящийся в центре глобулы белка хромофор с молекулами растворителя и являющийся структурным механизмом, обеспечивающим эффективную генерацию активных форм кислорода этими белками [3, 4].

Созданный первым, генетически кодируемый фотосенсибилизатор - белок KillerRed - при освещении зеленым или оранжевым светом производит активные формы кислорода и демонстрирует на три порядка более высокий уровень фототоксичности, чем другие флуоресцентные белки [2]. В зависимости от клеточной локализации и дозы светового облучения активные 
формы кислорода, генерируемые KillerRed, могут приводить K различным ффизиологическим последствиям, от инактивации белка слияния [2] до остановки клеточного деления [5, 6] и гибели клеток через некроз или апоптоз [2, 7].

Благодаря этим свойствам KillerRed используют в качестве оптогенетического инструмента в клеточной биологии для инактивации белков светом, изучения внутриклеточного окислительного стресса, а также для уничтожения интересующих экспериментатора клеточных популяций. KillerRed был также использован в качестве фотосенсибилизатора для лечения опухолей в модельных системах [7-9].

На основе KillerRed были созданы другие генетически кодируемые фотосенсибилизаторы, генерирующие активные формы кислорода: SuperNova, спектрально близкий к KillerRed мономерный вариант белка [10], и спектрально отличные от них оранжевый флуоресцентный белок KillerOrange [11] и зеленый флуоресцентный белок SuperNova Green [12]. Кроме того, на основе неродственных флуоресцентным белкам флавопротеинов были разработаны фотосенсибилизаторы miniSOG и Pp2FbFP и другие, генерирующие синглетный кислород при облучении синим светом [13, 14].

K сожалению, ни один из созданных на сегодняшний день фотосенсибилизаторов с флуоресценцией в зеленой области спектра нельзя назвать универсальным для широкого круга задач из-за неполного или медленного созревания хромофрора, различных типов генерируемых активных форм кислорода, или зависимости работы белка от доступности внешнего хромофора [15]. Целью настоящей работы было найти мутантный вариант KillerRed, который не формировал бы DsRed-подобный «красный» хромофор и мог служить основой для разработки нового поколения фотосенсибилизаторов с флуоресценцией в зеленой области спектра.

\section{МАТЕРИАЛЫ И МЕТОДЫ}

\section{Амплификация ДНК и анализ продуктов амплификации}

Амплификацию ДНК проводили с использованием набора Encyclo PCR Kit (Евроген; Россия) на приборе PTC-200 Thermal Cycler (MJ Research; США). Анализ продуктов амплификации проводили в 1-2\%-м агарозном геле. В качестве красителя использовали бромистый этидий в концентрации 0,5 мкг/мл.

\section{Создание библиотек случайных мутантов для направленной эволюции}

При создании библиотеки мутантов белка KillerRed использовали протокол мутагенеза, основанный на методе ПЦР с ошибками. В реакционную смесь добавляли соли марганца и определенное соотношение нуклеотидтрифосфатов, что в среднем приводило к 8 нуклеотидным ошибкам на 1000 амплифицированных нуклеотидов за 25 циклов ПЦР.

Перед проведением электротрансформации с целью удаления солей реакцию лигирования очищали с использованием набора для очистки ДНК Cleanup Mini (Евроген; Россия). Продукты лигирования смывали с колонки с помощью 10 мкл $\mathrm{mQ}$. Электрокомпетентные клетки в количестве 40 мкл размораживали при $0{ }^{\circ} \mathrm{C}$ и в размороженные клетки вносили 5 мкл реакции лигирования. Клетки переносили в предварительно охлажденную кювету для электропорации (BioRad; CША) и производили электропорацию в приборе MicroPulser (BioRad; США). Сразу после этого в кювету добавляли 3 мл среды SOB, полученную бактериальную суспензию переносили в пластиковые пробирки объемом 1,5 мл и инкубировали 1 ч в термостате при температуре $37{ }^{\circ} \mathrm{C}$. Бактериальную суспензию высевали на агар, приготовленный на основе среды LB, и инкубировали при температуре $37{ }^{\circ} \mathrm{C}$ в течение 18 ч. Средняя плотность колоний E. coli составляла 5000 на чашку Петри, общее разнообразие мутантов в библиотеке составило около 100000 клонов. Количество флуоресцентных колоний $-22 \%$.

\section{Экспрессия и очистка рекомбинантных белков}

E. coli штамма XL1 Blue выращивали в колбах объемом 800 мл, индуцировали изопропил- $\beta-D-1$ тиогалактопиранозидом до конечной концентрации 0,5 мМ и инкубировали при перемешивании в течение 3 ч. Далее все операции по выделению белка проводили на льду. Культуру клеток центрифугировали, супернатант сливали, осадок ресуспендировали в 4 мл фосфатного буфера $(\mathrm{pH} 7,4)$. Клетки разрушали ультразвуком, используя соникатор Sonics Vibra Cell (Sonics \& Materials; CШA), и снова центрифугировали. Супернатант переносили в чистую пробирку и добавляли 400 мкл металл-аффинной смолы Talon (Clontech; США), уравновешенной фосфатным бусрером. Пробирку помещали в шейкер на 1 ч 200 об./мин при комнатной температуре, после чего металл-аффинную смолу с белком несколько раз промывали фоссратным буфером. Затем элюировали белок раствором фосфатного бусрера, содержащего 250 мМ имидазола.

\section{РЕЗУЛЬТАТЫ ИССЛЕДОВАНИЯ}

Для поиска мутантного варианта KillerRed с флуоресценцией в зеленой области спектра мы провели случайный мутагенез. Библиотека мутантов KillerRed была клонирована в бактериальный экспрессионный вектор под контроль промотора с высокой фоновой экспрессией, трансформирована в E. coli и выращена на чашках Петри без индукции. Мы визуально скринировали бактериальные колонии при облучении светом 400 нм и 480 нм для

Таблица. Аминокислотные последовательности описанных в работе белков. Остатки, формирующие хромофор, выделены фиолетовым цветом, а позиции, содержащие мутации, оранжевым

\begin{tabular}{|c|c|}
\hline $\begin{array}{l}\text { Последовательность белка KillerRed I64L D114G T115S, } \\
\text { идентифицированного в настоящей работе }\end{array}$ & $\begin{array}{l}\text { MRGSHHHHHHGSEGGPALFQSDMTFKIFIDGEVNGQKFTIVADGSSKFPHGDFNVHAVCETGK } \\
\text { LPMSWKPICHLLQYGEPFFARYPDGISHFAQECFPEGLSIDRTVRFENDGTMTSHHTYELDGSC } \\
\text { VVSRITVNCDGFQPDGPIMRDQLVDILPNETHMFPHGPNAVRQLAFIGFTTADGGLMMGHFDS } \\
\text { KMTFNGSRAIEIPGPHFVTIITKQMRDTSDKRDHVCQREVAYAHSVPRITSAIGSDED }\end{array}$ \\
\hline Последовательность белка KillerRed & $\begin{array}{l}\text { MRGSHHHHHHGSEGGPALFQSDMTFKIFIDGEVNGQKFTIVADGSSKFPHGDFNVHAVCETGK } \\
\text { LPMSWKPICHLIQYGEPFFARYPDGISHFAQECFPEGLSIDRTVRFENDGTMTSHHTYELDDTCV } \\
\text { VSRITVNCDGFQPDGPIMRDQLVDILPNETHMFPHGPNAVRQLAFIGFTTADGGLMMGHFDSK } \\
\text { MTFNGSRAIEIPGPHFVTIITKQMRDTSDKRDHVCQREVAYAHSVPRITSAIGSDED }\end{array}$ \\
\hline
\end{tabular}




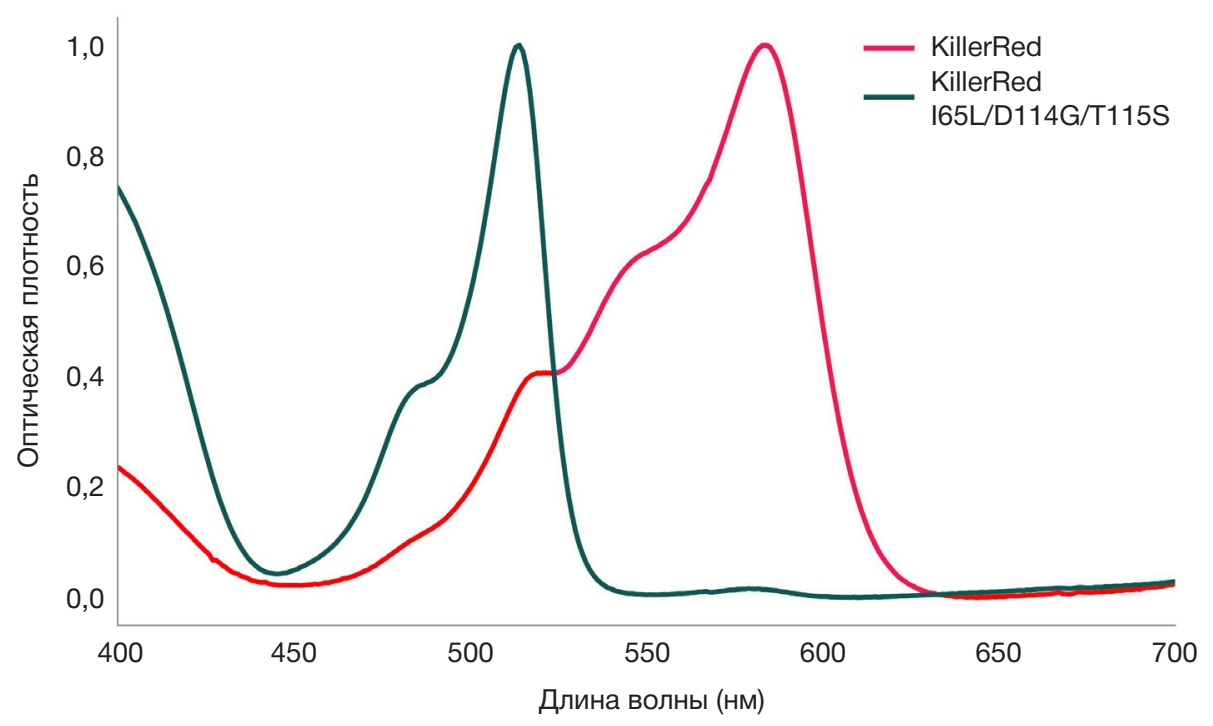

Рис. 1. Спектры поглощения очищенных препаратов белков KillerRed и KillerRed I64L/D114G/T115S

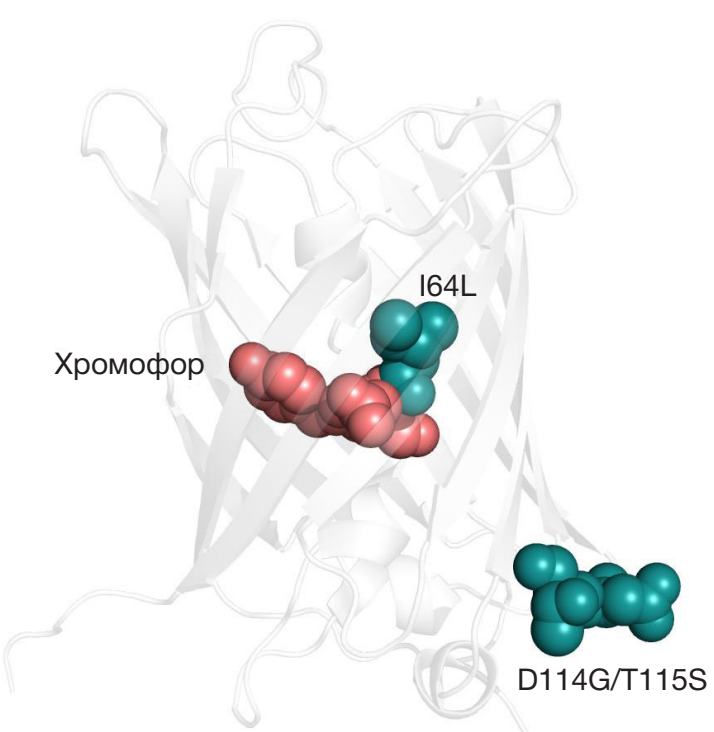

Рис. 2. Положение хромофора и мутаций I64L/D114G/T115S в структуре белка KillerRed

идентификации мутантов, обладающих значительной фрлуоресценцией в зеленой области спектра.

В результате скрининга был отобран мутант KillerRed 164L/D114G/T115S (см. табл.), который практически не обладал фрлуоресценцией в красной области спектра, зато обладал заметной зеленой фллуоресценцией при облучении светом 480 нм (здесь и далее нумерация позиций в белке указана по традиционной нотации, согласно которой хромофор формируют аминокислоты в позициях 65-67 [1]). Подобные спектральные свойства свидетельствовали в пользу формирования «классического» GFP-подобного хромофора вместо DsRed-подобного хромофрора, формируемого родительским KillerRed.

Поскольку белки с GFP- и DsRed-подобными хромофорами формируют легко отличимые друг от друга характерные спектры поглощения, мы получили препараты очищенного белка для мутантного белка KillerRed I64L/D114G/T115S и родительского KillerRed (рис. 1). Спектр поглощения очищенного KillerRed I64L D114G T115S действительно существенно отличался от спектра поглощения KillerRed и демонстрировал пик с максимумом в зеленой области спектра (514 нм) и характерным для GFP-подобных хромофоров гипсохромно сдвинутым плечом.

\section{ОБСУЖДЕНИЕ РЕЗУЛЬТАТОВ}

Отсутствие пика в области 550-600 нм на спектре поглощения KillerRed I64L/D114G/T115S свидетельствует о том, что внесенные мутации почти полностью предотвращают формирование DsRed-подобного хромофора, образующегося в родительском белке. Формируемый вместо этого пик с максимумом в области 514 нм и характерным плечом в области 480-485 нм позволяет предполагать, что катализ хромофора останавливается на «классическом» GFP-подобном хромосоре [1].

Представляются интересными мутации, обнаруженные в отобранном нами варианте KillerRed. Так, мутации в позиции 64 ранее уже были описаны как влияющие на созревание хромофора: например, в Aequorea victoria GFP мутация F64L улучшает созревание хромофора при экспрессии при $37^{\circ} \mathrm{C}$, а в хромобелке из Acropora millepora мутация S64C меняет цвет белка [16]. Мутации D114G и T115S находятся в соседних остатках на петле, соединяющей $\beta$-слои 5 и 6 (рис. 2), и, предположительно, могут участвовать в адаптации структуры $\beta$-бочонка белка к замене изолейцина на лейцин в позиции 64. 


\section{ВЫВОДЬ}

Описанный в настоящей работе мутант KillerRed представляет собой перспективный вариант для дальнейшей направленной эволюции с целью создания нового поколения генетически кодируемых фотосенсибилизаторов с флуоресценцией в зеленой области спектра. В отличие от других разработанных на сегодняшний день спектральных вариантов KillerRed, мутант KillerRed I64L/D114G/T115S формирует хромофор на основе тирозина и обладает флуоресценцией в зеленой области спектра.

\section{Литература}

1. Chudakov DM, Matz MV, Lukyanov S, Lukyanov KA. Fluorescent proteins and their applications in imaging living cells and tissues. Physiol Rev. 2010; (9)0: 1103-63. DOl:10.1152/ physrev.00038.2009/=.

2. Bulina ME, Chudakov DM, Britanova OV, Yanushevich YG, Staroverov DB, Chepurnykh TV, et al. A genetically encoded photosensitizer. Nat Biotechnol. 2006; (24): 95-9. DOl:10.1038/ nbt1175.

3. Pletneva NV, Pletnev VZ, Sarkisyan KS, Gorbachev DA, Egorov ES, Mishin AS, et al. Crystal Structure of Phototoxic Orange Fluorescent Proteins with a Tryptophan-Based Chromophore. PLoS One. 2015; (10): e0145740. DOl:10.1371/journal.pone.0145740.

4. Pletnev S, Gurskaya NG, Pletneva NV, Lukyanov KA, Chudakov DM, Martynov $\mathrm{VI}$, et al. Structural basis for phototoxicity of the genetically encoded photosensitizer KillerRed. J Biol Chem. 2009; (284): 32028-39. DOl:10.1074/jbc.M109.054973.

5. Serebrovskaya EO, Gorodnicheva TV, Ermakova GV, Solovieva EA Sharonov GV, Zagaynova EV, et al. Light-induced blockage of cel division with a chromatin-targeted phototoxic fluorescent protein. Biochem J. 2011; (435): 65-71. DOI:10.1042/BJ20101217.

6. Lan L, Nakajima S, Wei L, Sun L, Hsieh C-L, Sobol RW, et al. Novel method for site-specific induction of oxidative DNA damage reveals differences in recruitment of repair proteins to heterochromatin and euchromatin. Nucleic Acids Res. 2014; (42): 2330-45. DOI:10.1093/nar/gkt1233.

7. Shirmanova MV, Serebrovskaya EO, Lukyanov KA, Snopova LB, Sirotkina MA, Prodanetz NN, et al. Phototoxic effects of fluorescent protein KillerRed on tumor cells in mice. J Biophotonics. 2013; (6): 283-90. DOI:10.1002/jbio.201200056.

8. Kuznetsova DS, Shirmanova MV, Dudenkova W, Subochev PV, Turchin IV, Zagaynova EV, et al. Photobleaching and phototoxicity of KillerRed in tumor spheroids induced by continuous wave and pulsed laser illumination. J Biophotonics. 2015; 9999.

\section{References}

1. Chudakov DM, Matz MV, Lukyanov S, Lukyanov KA. Fluorescent proteins and their applications in imaging living cells and tissues. Physiol Rev. 2010; (9)0: 1103-63. DOl:10.1152/ physrev.00038.2009/=.

2. Bulina ME, Chudakov DM, Britanova OV, Yanushevich YG, Staroverov DB, Chepurnykh TV, et al. A genetically encoded photosensitizer. Nat Biotechnol. 2006; (24): 95-9. DOl:10.1038/ nbt1175.

3. Pletneva NV, Pletnev VZ, Sarkisyan KS, Gorbachev DA, Egorov ES, Mishin AS, et al. Crystal Structure of Phototoxic Orange Fluorescent Proteins with a Tryptophan-Based Chromophore. PLoS One. 2015; (10): e0145740. DOl:10.1371/journal.pone.0145740.

4. Pletnev S, Gurskaya NG, Pletneva NV, Lukyanov KA, Chudakov DM, Martynov VI, et al. Structural basis for phototoxicity of the genetically encoded photosensitizer KillerRed. J Biol Chem. 2009; (284): 32028-39. DOI:10.1074/jbc.M109.054973.

5. Serebrovskaya EO, Gorodnicheva TV, Ermakova GV, Solovieva EA Sharonov GV, Zagaynova EV, et al. Light-induced blockage of cell division with a chromatin-targeted phototoxic fluorescent protein. Biochem J. 2011; (435): 65-71. DOI:10.1042/BJ20101217.

6. Lan L, Nakajima S, Wei L, Sun L, Hsieh C-L, Sobol RW, et al. Novel method for site-specific induction of oxidative DNA damage reveals differences in recruitment of repair proteins to
DOl:10.1002/jbio.201400130.

9. Yan L, Kanada M, Zhang J, Okazaki S, Terakawa S. Photodynamic Treatment of Tumor with Bacteria Expressing KillerRed. PLoS One. 2015; (10): e0131518. DOl:10.1371/journal.pone.0131518.

10. Takemoto K, Matsuda T, Sakai N, Fu D, Noda M, Uchiyama S, et al. SuperNova, a monomeric photosensitizing fluorescent protein for chromophore-assisted light inactivation. Sci Rep. 2013; (3): 2629. DOI:10.1038/srep02629.

11. Sarkisyan KS, Zlobovskaya OA, Gorbachev DA, Bozhanova NG Sharonov GV, Staroverov DB, et al. KillerOrange, a Genetically Encoded Photosensitizer Activated by Blue and Green Light. PLoS One. 2015; (10): e0145287. DOI:10.1371/journal.pone.0145287.

12. Riani YD, Matsuda T, Takemoto K, Nagai T. Green monomeric photosensitizing fluorescent protein for photo-inducible protein inactivation and cell ablation. BMC Biol. 2018; (16): 50. DOI:10.1186/s12915-018-0514-7.

13. Shu X, Lev-Ram V, Deerinck TJ, Qi Y, Ramko EB, Davidson MW, et al. A genetically encoded tag for correlated light and electron microscopy of intact cells, tissues, and organisms. PLoS Biol. 2011; (9): e1001041. DOl:10.1371/journal.pbio.1001041.

14. Torra J, Burgos-Caminal A, Endres S, Wingen M, Drepper T, Gensch T, et al. Singlet oxygen photosensitisation by the fluorescent protein Pp2FbFP L30M, a novel derivative of Pseudomonas putida flavin-binding Pp2FbFP. Photochem Photobiol Sci. 2015; (14) 280-7. DOI:10.1039/c4pp00338a.

15. Acharya A, Bogdanov AM, Grigorenko BL, Bravaya KB, Nemukhin AV, Lukyanov KA, et al. Photoinduced Chemistry in Fluorescent Proteins: Curse or Blessing? Chem Rev. 2017; (117): 758-95. DOl:10.1021/acs.chemrev.6b00238.

16. Alieva NO, Konzen KA, Field SF, Meleshkevitch EA, Hunt ME, Beltran-Ramirez V, et al. Diversity and evolution of coral fluorescent proteins. PLoS One. 2008; (3): e2680. DOI:10.1371/journal. pone.0002680 heterochromatin and euchromatin. Nucleic Acids Res. 2014; (42): 2330-45. DOI:10.1093/nar/gkt1233.

7. Shirmanova MV, Serebrovskaya EO, Lukyanov KA, Snopova LB, Sirotkina MA, Prodanetz NN, et al. Phototoxic effects of fluorescent protein KillerRed on tumor cells in mice. J Biophotonics. 2013; (6) 283-90. DOI:10.1002/jbio.201200056.

8. Kuznetsova DS, Shirmanova MV, Dudenkova W, Subochev PV, Turchin IV, Zagaynova EV, et al. Photobleaching and phototoxicity of KillerRed in tumor spheroids induced by continuous wave and pulsed laser illumination. J Biophotonics. 2015; 9999. DOl:10.1002/jbio.201400130.

9. Yan L, Kanada M, Zhang J, Okazaki S, Terakawa S. Photodynamic Treatment of Tumor with Bacteria Expressing KillerRed. PLoS One. 2015; (10): e0131518. DOI:10.1371/journal.pone.0131518.

10. Takemoto K, Matsuda T, Sakai N, Fu D, Noda M, Uchiyama S, et al. SuperNova, a monomeric photosensitizing fluorescent protein for chromophore-assisted light inactivation. Sci Rep. 2013; (3): 2629. DOI:10.1038/srep02629.

11. Sarkisyan KS, Zlobovskaya OA, Gorbachev DA, Bozhanova NG, Sharonov GV, Staroverov DB, et al. KillerOrange, a Genetically Encoded Photosensitizer Activated by Blue and Green Light. PLoS One. 2015; (10): e0145287. DOl:10.1371/journal pone.0145287. 12. Riani YD, Matsuda T, Takemoto K, Nagai T. Green monomeric 
photosensitizing fluorescent protein for photo-inducible protein inactivation and cell ablation. BMC Biol. 2018; (16): 50. DOI:10.1186/s12915-018-0514-7.

13. Shu X, Lev-Ram V, Deerinck TJ, Qi Y, Ramko EB, Davidson MW, et al. A genetically encoded tag for correlated light and electron microscopy of intact cells, tissues, and organisms. PLoS Biol. 2011; (9): e1001041. DOl:10.1371/journal.pbio.1001041.

14. Torra J, Burgos-Caminal A, Endres S, Wingen M, Drepper T, Gensch T, et al. Singlet oxygen photosensitisation by the fluorescent protein Pp2FbFP L30M, a novel derivative of Pseudomonas putida flavin-binding Pp2FbFP. Photochem Photobiol Sci. 2015; (14): 280-7. DOl:10.1039/c4pp00338a.

15. Acharya A, Bogdanov AM, Grigorenko BL, Bravaya KB, Nemukhin AV, Lukyanov KA, et al. Photoinduced Chemistry in Fluorescent Proteins: Curse or Blessing? Chem Rev. 2017; (117): 758-95. DOl:10.1021/acs.chemrev.6b00238.

16. Alieva NO, Konzen KA, Field SF, Meleshkevitch EA, Hunt ME, Beltran-Ramirez V, et al. Diversity and evolution of coral fluorescent proteins. PLoS One. 2008; (3): e2680. DOl:10.1371/journal. pone.0002680. 